\section{THE RECENT EARTHQUAKES}

THE earthquake record of the past week is a long and disastrous one. An earthquake of wide area and extraordinary intensity took place soon after to o'clock on the night of August 3I, throughout nearly the entire portion of the United States east of the Mississippi, shocks being felt from the Gulf of Mexico northwards and from the Mississippi eastward to the Atlantic. The shocks were especially severe at Montgomery (Alabama), Cleveland (Ohio), Meadville (Pennsylvania), Raleigh (North Carolina), and Indianapolis (Indiana). In New York, Washington, Detroit, Milwaukee, Cincinnati, Louisville, Chattanooga, and other places severe undulations were felt. The shock was light at Chicago, and west of the Mississippi at Omaha, Ogden, or San Francisco no disturbance was felt. The bounds of the disturbed area are thus roughly defined to be the Mississippi, the Atlantic, the Gulf of Mexico, the Lakes and the St. Lawrence. Georgia and South Carolina appear to have been the most severely visited of all the States. At Augusta, in the former State, there were ten distinct shocks between 9.15 and 10.45 p.m., and the streets were filled with the terrified population. At Savannah five shocks were felt. Sharp shocks were also felt in New Jersey, and vibrations as far north as Philadelphia, Prof. Newcomb, of the Nautical Almanac, Washington, reports that the first shock occurred at 9.53.20, and the second at 9.54.30, lasting until 9.59. The Signal Service Bureau at Washington reports that four distinct shocks were felt there. The first began at 9.54, and lasted 40 seconds, the second at 10.0.4, the third at IO. IO, and another at 10.30. Charleston, in South Carolina, suffered most severely, - the streets were blocked with fallen buildings, telegraph poles, and tangled wires. The population spent the night in the streets. As usual after violent earthquakes, fires broke out. The principal business quarter and two-thirds of the dwellinghouses have been destroyed, and the town was isolated from the outside world, the bridges and railroads being all destroyed. Sullivan's Island, a watering-place near Charleston, wa submerged by a tidal wave. At Columbia, in the same State, ten distinct shocks of earthquake were felt, the last at ro.25 on the morning of the Ist inst. Fresh shocks were felt in the afternoon of the Ist at Augusta, Charleston, and Columbus, and during the same day throughout North and South Carolina and Georgia, and many fissures opened, emitting fresh water, white sand, and blue mud from a great depth. At Ir.55 on the night of the Ist another violent shock in Charleston brought down several houses. Since that date, shocks of more or less violence have continued up to the present in the States above-mentioned.

This earthquake is believed to have disturbed a greater extent of territory than any earthquake on record. Twenty-two States, covering an area of a million square miles, were affected. Toronto and London in Ontario are said to have felt some symptoms of disturbance. The natural phenomena accompanying the earthquake are curious. The fissures in the earth, whence the sulphurous fumes arise, are not confined to Charleston itself, but are found for miles round the town. From these fissures is exuded sand, white in some places, and red in others. From other openings brackish tepid water has been spouted from 15 to 20 feet high. These fissures are not made by the sinking of the ground, but by the tearing apart of the earth's crust. Sometimes they are 20 yards long, and they are of uncertain depth. They could be seen to widen and contract during the shocks, and sand, water, and an unfamiliar substance of an oily paste character was expelled. After these cjections mound-like cones remained. The water in the wells was observed to rise and fall. At Summerville, the holiday resort of the people of Charleston, detonations were heard about once in ten minutes in all directions, but they appeared to have no relation with the earthquake shocks. There arc some doubtful reports of flames being seen proceeding from the ground. The atmospbere during the earlier phenomena was oppressive, and so still was the air that the lamps burned out of doors for hours without flickering. A violent shock which visited part of South Carolina at II o'clock on the night of the 5th, was followed after an interval of five minutes by two brilliant meteors which shot across the sky fram north to south. A curious occurrence is reported by the Correspondent of the Times. He says that on the 2nd inst. at Charleston "two showers of morsels of flints, abraded by mechanical action, were noticed, some having been recently fractured. The first shower fell at 7.30 a.m., and the second at Ir." At the Signal Office at Wash- ington the self-registering wind-vane shows a horizontal mark preceding and sub equent to the shaking, denoting a mild, steady, and almost invariable breeze. But during the 30 or 40 seconds of the most violent shaking, the marks indicate that the pencil point moved up and down the paper many times with great rapidity. The effect of the earthquake at sea is described by the captain of the steamer Palatka. He had just left Charleston, and was twelve miles off the harbour of Port Royal, in eight fathoms and a half, when he heard a terrible rumbling, lasting a minute and a half. There had been a heavy sea from the south-east, but when the rumbling began the wave-motion ceased, and the waters remained in a perfect calm until the rumbling ended, when the swell was again manifest. The wind was south-east and light, the weather cloudy, the barometer $30^{\circ} \mathrm{or}$, and the thermometer at $80^{\circ}$. The ship's timbers vibratcd strongly. No unusual meteorological conditions prevailed at Charleston before, during, or after the earthquake on the first day, according to the officer of the Signal Service. Profs. Mendenhall and $\mathrm{M}^{\circ}$ Gee are investigating the effects of the earthquake at Charleston and Summerville.

Earthquakes are also reported from Malaga, where a severe shock occurred, on the Ist and morning of the 2nd ; from Santa Cruz, in California, at $\mathrm{Ir} .45$ on the morning of the $2 \mathrm{nd}$, where it is described as not violent, but long-continued; and from Smyrna, where several sharp shocks were felt between 10 and I 2 on the night of the $3 \mathbf{I s t}$, that is almost simultaneously with the American earthquake. A telegram dated the 5th inst., from Athens, reports that the shocks at Pyrgos have been renewed.

We have received several letters relating to the earthquake in the Eastern Mediterranean of the 27 th ult. Prof. Forel, of Morges, writes that, as it extended at least from Alexandria to Berne, it covered an area of about $25^{\circ}$ diameter. At Berne the seismograph of the Observatory marked the shock at 10 h. $36 \mathrm{~m}$. I6s. local time, corresponding to $22 \mathrm{~h}$. $6 \mathrm{~m}$. 3os. Greenwich time. If, continues Prof. Forel, we admit, in accordance with the times recorded at Benevento, Fermo, Pesaro, and Zante, that the time of the shock at the centre was $22 \mathrm{~h}$. Im. 20s. \pm 7os. Green wich time, then the seismic wave would have taken $5 \mathrm{~m}$. IOs, to reach Berne. It is said that the shock was felt at Alexandria 15 minutes after midnight, in which case progress in that direction was a little slower; put into Greenwich time, this would be $22 \mathrm{~h}$. $15 \mathrm{~m}$., or about $14 \mathrm{~m}$. for transmission from Zante to Alexandria. In Switzerland a small preparatory shock was felt in the Alps of Vaud, about II minutes before the Berne shock. Mr. Henry Simon, writing from Engelberg, in Obwalden, states that the shock was distinctly felt there as a swaying motion about 10.20 by several of the visitors and in different houses.

\section{THE SCOTTISH METEOROLOGICAI, SOCIETY}

THE following is an abstract of the Report of the Cuncil read at the meeting of the Scottish Meteorological Society held on July 22 :-

Since the general meeting of the Society in March, the num. ber of the Society's stations has remained the same.

The membership of the Society now numbers 719 , being 7 more than at the meeting in March.

The preparation of a fourth paper on the climate of the British Islands, dealing with the monthly rainfall for the twenty years $1866-85$, is now far advanced, and the results are practically and scientifically of great interest.

Much time has been spent in preparing for the press the whole of the observations of the Ben Nevis Observatory and those of the station at Fort William for the two years and a half from December I 883 to May 1886 . The volume will shortly be in the hands of scientific men in all parts of the world. In connection with these valuable observations, the investigation of the important question of the bearing of the results on the weather of these islands is steadily advancing.

The position of the Ben Nevis Observatory on an elevated isolated peak, and the adjoining low-level station at Fort William being close to the sea, and on a bank sloping down to it, renders this pair of stations second to none anywhere yet established for the investigation of some of the fundamental facts of meteorology. Among the more important of these questions is the determination of the rate of decrease of temperature with height, and the rate of diminution of atmospheric pressure with height, for different atmospheric temperatures and sea-level pressures. 
In these aspects the observations $f$,r the two years and a half from December 1883 to May 1886 have now been discussed. As regards decrease of temperature with height, it is shown to be at the rate of $\mathrm{I}^{\circ} \mathrm{F}$. for every 270 feet of ascent-a rate which closely agrees with the results of the most carefully conducted balloon ascents, and of th sse other pairs of stations over the w.rld which are so situated as to yield trustworthy results for the inquiry. Ben Nevis Observatory and the Fort William station are among the very few such groups of stations that have yet been anywhere established.

In researches into weather phenomena and weather prognastics the most important point to determine is the normal difference between atmospheric pressure at the top of the Ben and at Fort William for the different atmospheric temperatures and sea-level pressures. This was empirically calculated from the observations, and thereafter the departures from the normals were ascertained for the five observations of each day since the Osservatory was opened. The results showed a diminution of pressure from the calculated normals during the occurrence of high winds at the Observatory. The difference not unfrequently amounts to the tenth of an inch, and on one day the five con secutive observations showed differences of about a tenth-and-a. half inch. This diminution of pressure is doubtless occasioned by the winds, as they brush past the Observatory buildings, partially sucking out the air from the interior, thus lowering the pressure. This does not occur till the velocity rises to or exceeds the rate of 30 miles an hour.

It thus became necessary to recalculate the normals for pressure, using in the computations only those observations which were made when the velocity of the wind fell short of 30 miles an hour. This recalculation has recently been conpleted, and the inquiry as to the bearing of the Ben Nevis observation; on the weather of the British Islands is being pushed forward.

The work at the Ben Nevis Observatory continues to be discharged by Mr. Omond and his a sistants in a way that leaves nothing to be desired. Since the last meeting of the Society Mr. Omond has contributed a valuable paper to the Royal Society of Edinburgh, on the observations of wind force recorded at the Observatory. From a comparison of the results obtained from the registrations of Prof. Chrystal's anemometer, and the estimations of the force of the wind made by the observers on scale o to I2, he has determined the velocity in miles per hour for each figure of the scale, $1,2,3$, \&c. The highe t figure for which the double observations were sufficiently numerous, so as to give a good average, was 8 , which was found to be equivalent to a rate of 73 miles an hour. This velocity is of frequent occurrence; and as regards the higher force $\mathrm{II}$, which occasionally occurs, Mr. Omond estimates its equivalent at 120 miles an hour. Observations on the rain band have been undertaken by Mr. Kankin, the first assistant.

The hygrometric observations made by Mr. H. N. Dickson at the Scottish Marine Station and the Observatory have now been partially discu sed by him, and the results submitted to a recent meeting of the Royal Society of Edinburgh. These results are of considerable value in determining how far Glaisher's factors, so largely used by meteorologists in hygrometric inquiries, may be used satisfactorily. As regards the remarkably dry states of the atmosphere, which are so prominent a feature in the climate of the Ben, Glaisher's factors are altogether inapplicable, and hence the hygrometric observations of the Observatory, therefore, will require a specially constructed set of tables.

The zoological work at the Marine Station ha; been carried on regularly. The principal work since March last has been the examination of the ova and larvæ of fishes. Endeavours have been made to obtain the early stages of as many species as possible, and as only a few species breed at one season, considerable success has been achieved. The results of this work have been communicated to the Royal Society.

Since the last meeting the Phy:ical Department of the Scottish Marine Station has been actively engaged in carrying on observations of temperature and water-density in the Firth of Forth and the Clyde districts. Meteorological observations are continued at Granton, and the temperature of a number of rivers (the Thurso at three points, the Tummel, Forth at two points, 'Teith, Tweed, and Derwent) is being observed daily. Mr. Morrison has continued his monthly trips to Loch Lomond and Loch Katrine, where he has observed the vertical distribution of temperature. The work on the Firth of Forth, usually carried on solely by serial temperature observations made on the Medzusa inside the Isle of May, has been supplemented by the captain of one of the Granton steam-trawlers, who was supplied with a deepsea thermometer, and has been using it to good purpose in the North Sea fron 30 to 60 miles off shore. The tidal variations of salinity in the estuary of the Forth were investigated by Dr. Mill and Mr. Morrison during a week's stay at Kincardine, and the result embodied in a paper read to the Royal Society of Edinburgh. 'Two trips of the Medusa on the Clyde supplied data for a paper which is presented to this meeting, as well as a quantity of observations not yet fully worked up.

The work of collecting and discussing the sea temperatures around the coast of Scotland is being carried on by Dr. Mill and Mr. Morrison. Since last meeting the Meteorological Council of London has lent all the sea observations made at the Sc sttish Coast-Guard Stations from 1879 to 1885 ; and observations of river temperature made by direction of the Duke of Sutherland and Mr. Boyd, Peterhead, have also been received. The Government Grant Committee of the Royal Society of London has given a grant of 50 . towards the completion of this work. Thermometers have been lent for use in the deep water off Shetland to Mr. F. Coulson, who is at present on a dredging trip in his yacht in that locality. The National Fish Culture Association of England, which has been in correspond. ence with the station for some time as to physical observations, has now commenced operations at several light-ships and on board the mission-smacks in the North Sea.

Mr. John Murray, of the Challenger Expedition, made a com munication on the extent of the areas of the different mean annual rainfalls over the globe. He had been led to undertake this inquiry so as to find out the amount of material carried down from the land to the ocean, and which went to form ocean deposits. The amount of rain that fell upon the surface of the globe annually was estimated at about 34,000 to 35,000 cubic miles. Taking the inland drainage areas disconnected with the sea, such as the Sahara Desert, it is found that 77 cubic miles of rain fell upon these surfaces, which must be regarded as equivalent to the amount of evaporation. The Americans had calculated that 99 million millions of cubic feet of rain fell annually over the Mississippi drainage area. Calculating the outflow of the river, they estimated that only one-fourth of that water reached the ocean. By extending their inquiry over large areas, it was hoped that it would be made of some practical importance.

Dr. H R. Mill, of the Scottish Marine Station, read a paper on the temperature of the water in the Firth of Clyde and its connected lochs. The configuration of the water system was explained by means of a bathymetrical chart. Roughly speaking, the Firth of Clyde contained two tracts of deep water-one in which the water is over 70 fathoms deep, running up Kilbrannan Sound, and the other rather deeper between Arran and Asrshire-uniting with the first at the north of Arran, and continuing up Loch Fyne to near Ardrishaig, attainiug its greatest depth off Skate Island, near Tarbert, where it is 107 fathoms. These tracts of deep water are separated from the Atlantic by a broad plateau, which extends between the Mull of Cantyre and Girvan, and rises to within 25 fathoms of the surface. There are also three shallow lochs-Gareloch, Holy Loch, and Loch Ridden; and four deep lochs--Upper Loch Fyne, Loch Goil, Loch Strivan, and Loch Lon - -w which are shut off from communication with the outside waters by barrier. rising in some cases to within a few fathoms of the surface. Dr Mill then gave an account of the temperature in each of the regions as were ascertained during trips of the Medusa in April and June. He omitted, he said, discussing in detail the individual observations until fuller investigation gave the data for a general theory. In April, surface temperature over the whole Clyde district varied only from $42^{\circ}$ to $45^{\circ}$, and the temperature at considerable depths had a range of not more than half a degree $-4 \mathrm{I}^{\circ} \cdot 3$ to $4 \mathrm{I}^{\circ} \cdot 8$. The warmest water was found on the barrier plateau at the south end of the firth, and outside it, the deep lochs came next, and then the deep open basins. In all cases the temperature fell gradually, proceeding downwards for about Io or 15 fathoms, and then remained constant to the bottom. By June a considerable heating of the surface-layers had taken place, and the different regions had undergone change to a very different extent. The shallow lochs had been heated apparently from the surface and from the botto: $;$ the greatest rise in temperature was found beyond the platcau, then in the deep open basins, and the least in the deep lochs, one of 
which, Loch Goil, was only half a degree warmer than in April. The range of surface temperature in June was from $45^{\circ}$ to $53^{\circ}$, and of bottom temperature from $42^{\circ}$ to $47^{\circ} \cdot 3$, according to locality. Constant temperature to the bottom commenced at a much lower depth than in April. In the upper basin of Loch Long, which was discussed with more fulness, the surface-temperature was $48^{\circ} .4$, at 10 fathoms it was $44^{\circ} \cdot 2$, and from 55 fathoms to the bottom at 70 fathoms it was $44^{\circ}$. But between ro fathoms and 55 fathoms the water was colder than at either of these points, reaching its lowest temperature of $42^{\circ} .8$ at 20 fathoms. It thus appeared that a lenticular mass of water floated between the warmer strata, the opinion as to the cause of which was meantime reserved until further light can be thrown on the phenomenon. In the Clyde district, Dr. Mill said, physical configuration is the determining cause of differences of temperature, and it appears that as the season advances, warmth descends from the surface everywhere by conduction, and travels inward from the sea by conduction and convection. The study of water climate, he said, was likely to lead to important results, but it must be carried on by a large number of observers, who would note the temperature of rivers and of falling rain, before any degree of completeness could be obtained. The paper was illustrated by a series of admirable charts.

\section{SCIENTIFIC SERIALS}

THE Fourna! of the Franklin Institute, August.-Capt. O. E. Michaelis, the applications of electricity to the development of marksmanship. This is the conclusion of an interesting paper on chronoscopic and chronographic methods, illustrated by cuts of recent instruments.-W. Lewis, experiments on transmission of power by gearing (conclusion of the discussion). - F. Lynnwood Garrison, the microscopic structure of car-wheel iron.G. Richmond, the refrigeration-machine as a heater.-C. Hoele, a method of designing screw propellers. - F. E. Ives, correct colour-tone photography with ordinary gelatine bromide plates. A proposal to reduce the sensitiveness of the bromide films to the blue and green rays, by introducing into a plate-glass tank mixtures of aniline colour solutions, chiefly yellow and red, in certain proportions, thereby equalising the sensitiveness throughout the range of the visible spectrum.--Joshua Pusey, suggestions towards a simplified system of weather signals, termed the index weather-signal system.--P. E. Chase, Herschel and Jevon on density of the ether.

Annalen der Physik und Chemie, vol, xxviii. No. 8, August I886.-Prof. G. Quincke, electrical researches, No. xii., on the properties of dielectric fluids under strong electric forces. The dielectric constant of a number of liquids is examined by two methods, by attraction between two plane parallel plates immersed in the liquid, and by discharge of their charges through a galvanometer. High potentials were obtained by a Holtz machine, and measured by a long-range electrometer up to 30,000 volts. The results show that with high electric forces the dielectric constant is less than with lower electric forces; in other words, there exists an apparent tendency to saturation in inductive capacity. Measurements of the dielectric constant are always from Io to 50 per cent. higher when made by the balance-method than those made by the condenser discharge method. In different dielectric fluids the spark-distance for the same difference of potentials is different, and always much shorter than in air. The potential requisite to produce a spark within a dielectric liquid increases with the spark-length, but at a slower rate. The strength of a steady electric current in a dielectric fluid increases more rapidly than the electromotive force which produces it; an exception, apparently, to Ohm's law.-L. Sohncke, electrification of ice by water-friction. Experimental proof that water becomes negatively electrified and ice positively electrified by mutual friction. The author thinks thereby to explain the origin of thunderstorms by friction of cumulus and cirrus clouds. - E. Edlund, researches on the electromotive force of the electric spark. He finds the counterelectromotive force of the electric spark to be divisible into two parts, one at each pole, that at the positive pole decreasing, and that at the negative pole steadily increasing, as the air-pressure is diminished. He regards this as explaining the anomalies of unequal heating of the electrodes. -W. Donle, contributions to knowledge of the thermo-electric properties of electrolytes. According to these experiments the thermo-electromotive force between two electrolytes, such as solution of sulphate of copper and sulphuric acid is approximately proportional to the differences of temperature of the points of contact ; the proportionality varying in some way with the concentration of the solutions. The electromotive force is usually less with more concentrated solutions. Through the heated junction of a cbloride and a sulphate the current flows from chloride to sulphate.-F. Auerbach, on the electric conductivity of metal powders. Precipitated silver was used. The author finds an enormous reduction when the density is increased by mechanical force.R. Krïger, on a new method of determining the vertical intensity of a magnetic field. This method consists in sending an electric current radially through a horizontal copper disk suspended by a thin wire, and observing the rotation of the disk. R. Maurer, on the ratio of the sectional contraction to the longitudinal elongation produced in rods of glue-jelly. The rods were made of gelatine and water, and of gelatine and glycerine. One of the methods was an electrical one, consisting in observing the change of electrical resistance on stretching. These jelly rods exhibit the phenomena of residual strains very markedly.-M. Hamburger, researches on the duration of the impact of cylinders and spheres.-Dr. K. Noack, on the fluidity of absolute and diluted acetic acids. Curious minima of fluidity are observed by the author, varying with concentration and with temperature.-W. Miiller-Erzbach, the law of decrease of absorbing power with increasing distance.

\section{SOCIETIES AND ACADEMIES \\ EDINBURGH}

Royal Society, July I9.-Mr. Robert Gray, Vice-President, in the chair. - The Right Hon. Lord Rayleigh communicated a paper on the colours of thin plates. $\mathrm{He}$ has laid down on Maxwell's triangle of colours a curve representing the variation of the colours of thin plates as the thickness of the plates increases.-Prof. Dr. Fr. Meyer communicated a paper on algebraic knots. - Prof. Tait described Amagat's "manomètre à pistons libres."---Prof. C. G. Knott communicated a paper on the electrical properties of hydrogenised palladium. This paper contains the results of experiments on the resistance and thermoelectric properties of hydrogenium or hydrogenised palladium. Up to a temperature of about $200^{\circ} \mathrm{C}$. no special peculiarity is noticeable ; but at that temperature, or a little higher, hydrogen begins to escape from the wire, and this causes the particular specimen of hydrogenium to recover partially, if not wholly, its pure palladium characteristics. It is known that the resistance of a palladium wire charged with hydrogen at ordinary atmospheric temperatures increases at a rate almost strictly proportional to the amount of charge. The same law seems to hold at all temperatures up to $150^{\circ} \mathrm{C}$., and in such a way that the total increase of resistance of a given palladium wire for a given rise of temperature is nearly the same at all charges; or the temperature-coefficient for any particular specimen of hydrogenised wire is practically inversely proportional to the resistance as compared with the resistance of the wire in its pure uncharged state. Just before the hydrogen begins to escape, the resistance begins to increase somewhat more rapidly than at lower tem. peratures ; and this peculiarity is more marked in the specimens of higher charge. When once the hydrogen begins to escape, the resistance begins to fall off rapidly as the temperature rises to $300^{\circ} \mathrm{C}$. At this temperature the wire cannot be distinguished from pure palladium. In the thermo-electric experiments, peculiar irregularities appear at the higher temperatures, which seem to be due to the fact that the hydrogenium wire is unequally heated, and that the hydrogen, which is almost completely driven out of the heated portion of the wire, returns partially as the wire is cooled down again. In all cases at temperatures below $150^{\circ} \mathrm{C}$., the current is from pure palladium to hydrogenium through the hot junction, is probably proportional to the difference of temperature in each case, and is greater for the greater charge. Thermo-electrically, fully saturated hydrogenium lies between iron and copper at ordinary atmospheric temperatures. On the thermo-electric diagram the hydrogeniums of different charge are represented (up to a temperature of $150^{\circ} \mathrm{C}$.) by a series of straight lines parallel to palladium, whose thermoelectric powers at $0^{\circ} \mathrm{C}$. range roughly from -600 (pure palladium) to $+\mathbf{I} 400$ (saturated hydrogenium) expressed in C.G.S. units. (Compare Everett's "Units and Physical Constants," p. 15r.) 